\title{
Anatomic variation of cranial parasympathetic ganglia
}

Selma Siéssere
Mathias Vitti $^{\left({ }^{(a)}\right.}$
Luiz Gustavo de Sousa(c) $_{\text {Marisa Semprini }}$
Mamie Mizusaki lyomasa
Simone Cecílio Hallak Regalo(d)

(a) $\mathrm{PhD}$ in Anatomy, Assistant Professor; (b)Full Professors; (c)BSc (Biology), Laboratory Specialist in Anatomy; ${ }^{(d)}$ Associate Professors - Department of Morphology, Stomatology and Physiology, School of Dentistry of Ribeirão Preto, University of São Paulo.

\begin{abstract}
Having broad knowledge of anatomy is essential for practicing dentistry. Certain anatomical structures call for detailed studies due to their anatomical and functional importance. Nevertheless, some structures are difficult to visualize and identify due to their small volume and complicated access. Such is the case of the parasympathetic ganglia located in the cranial part of the autonomic nervous system, which include: the ciliary ganglion (located deeply in the orbit, laterally to the optic nerve), the pterygopalatine ganglion (located in the pterygopalatine fossa), the submandibular ganglion (located laterally to the hyoglossus muscle, below the lingual nerve), and the otic ganglion (located medially to the mandibular nerve, right beneath the oval foramen). The aim of this study was to present these structures in dissected anatomic specimens and perform a comparative analysis regarding location and morphology. The proximity of the ganglia and associated nerves were also analyzed, as well as the number and volume of fibers connected to them. Human heads were dissected by planes, partially removing the adjacent structures to the point we could reach the parasympathetic ganglia. With this study, we concluded that there was no significant variation regarding the location of the studied ganglia. Morphologically, our observations concur with previous classical descriptions of the parasympathetic ganglia, but we observed variations regarding the proximity of the otic ganglion to the mandibular nerve. We also observed that there were variations regarding the number and volume of fiber bundles connected to the submandibular, otic, and pterygopalatine ganglia.
\end{abstract}

Descriptors: Anatomy; Ganglia, parasympathetic.
Corresponding author:

Selma Siéssere

Faculdade de Odontologia de

Ribeirão Preto - USP

Depto. de Morfologia, Estomatologia

e Fisiologia

Avenida do Café, s/n

Ribeirão Preto - SP - Brazil

CEP: 14040-904

E-mail:selmas@forp.usp.br

Received for publication on Feb 07, 2007

Accepted for publication on May 16, 2007 


\section{Introduction}

A ganglion is a mass of nervous tissues found in some peripheral nerves. Ganglia are located on the roots of spinal nerves and on the sensitive roots of the trigeminal, facial, glossopharyngeal, vagus, and vestibulochoclear nerves. Ganglia also appear in association with the autonomic nervous system. Each ganglion is covered by a smooth and dense capsule of fibrous connective tissue, with cells similar to associated flattened fibrocytes, which extends to the nerves' perineurium, sending numerous extensions to the ganglion's interior. Ganglia vary considerably in size, shape ${ }^{1}$ and location. Hence, broad knowledge on these structures is essential in dentistry, due to their anatomical and functional importance. Thus, detailed studies are called for. However, some are difficult to visualize and identify due to their small volume and complicated access. Such is the case of the parasympathetic ganglia. Located in the cranial section of the autonomic nervous system, they are the ciliary, pterygopalatine, submandibular, and otic ganglia. These structures are commonly mentioned in literature, but not frequently observed in anatomical material. Hence, the aim of this work was to present the ciliary, pterygopalatine, submandibular, and otic ganglia in dissected anatomic pieces and perform a comparative analysis regarding location and morphology. The proximity of ganglia and associated nerves were also analyzed, as well as the number and volume of fiber bundles connected to them.

\section{Material and Methods}

Forty human adult heads (males and females, average age 40 years) from the Anatomy Laboratory, School of Dentistry of Ribeirão Preto, University of São Paulo were fixed in formalin $(10 \%)$ and later sectioned in a median plane with a manual saw. By planes, the dissection was performed using scalpels numbers 3 and 4, curved scissors (sharp and rhombpoint), iris nippers, retractors, osteotomes and loupe, partially removing the adjacent structures to the point we could reach the parasympathetic ganglia.

\section{Results}

After the dissection, we could see that in 28 human heads the ciliary ganglion was located deeply in the eye socket, in its posterior third, laterally to the optic nerve, and it was functionally attached to the oculomotor nerve. In the remaining 12 human heads, we observed that the ganglion occupies a posteroinferior, intermediate or anterosuperior position in respect to the common tendinous ring and optic nerve. Regarding morphology, the ciliary ganglion had a small, oval, and flattened shape, measuring approximately $1 \mathrm{x} 1 \mathrm{~mm}$.

The pterygopalatine ganglion was located in the pterygopalatine fossa and was functionally attached to the facial nerve. This ganglion had the largest size when compared to the other ganglia and it had a flattened form.

The submandibular ganglion was located laterally and superiorly to the hyoglossus muscle, later-

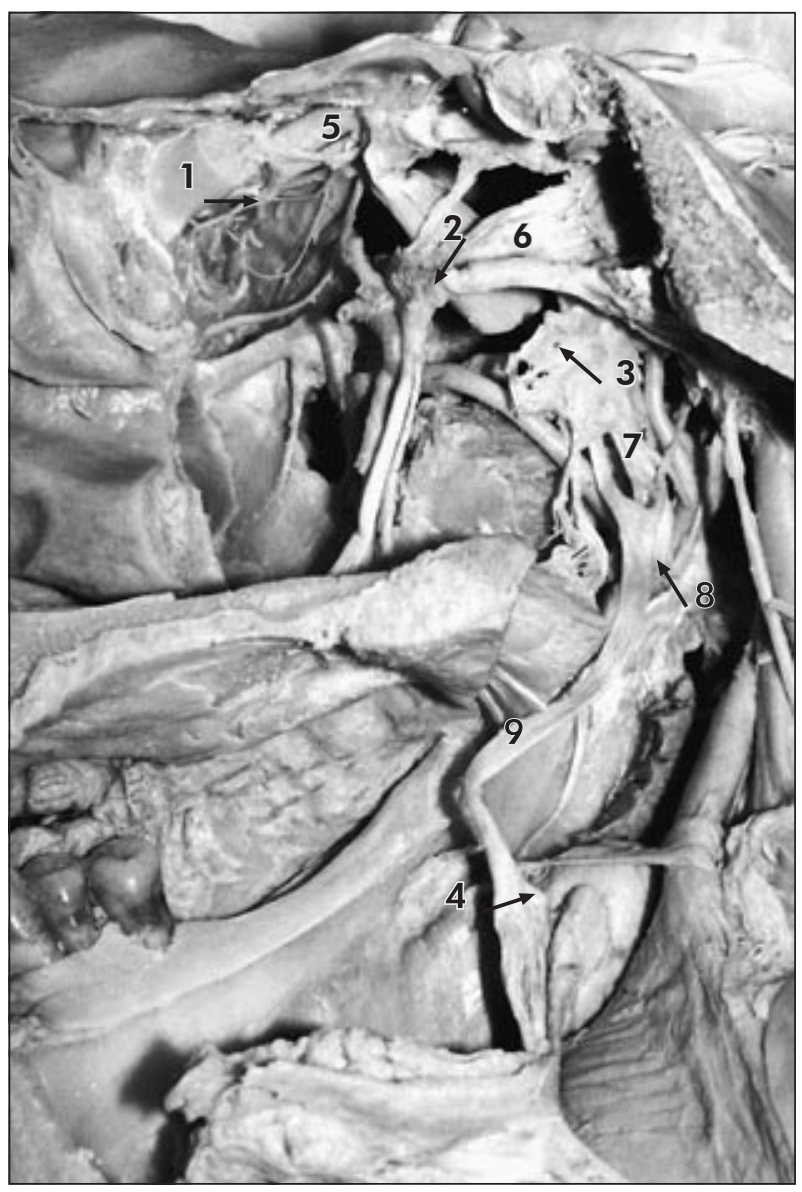

Figure 1 - Medial view of a human head (sagittal section). 1. Ciliary Ganglion; 2. Pterygopalatine Ganglion; 3. Otic Ganglion; 4. Submandibular Ganglion; 5. Optic Nerve; 6. Maxillary Nerve; 7. Mandibular Nerve; 8. Inferior Alveolar Nerve; 9. Lingual Nerve. 


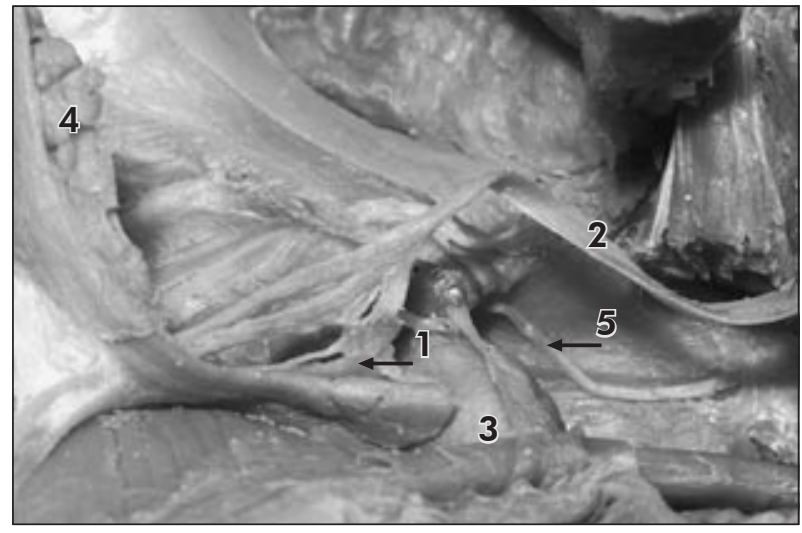

Figure 2 - Medial view of a mandible. 1. Submandibular Ganglion; 2. Lingual Nerve; 3. Submandibular Gland; 4. Sublingual Gland; 5. Mylohyoid Nerve.

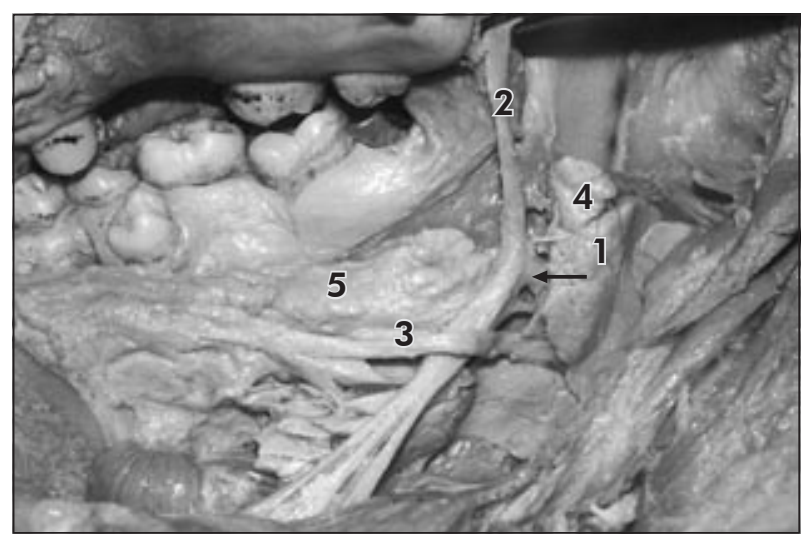

Figure 3 - Medial view of a mandible. 1. Submandibular Ganglion; 2. Lingual Nerve; 3. Major Sublingual Duct; 4. Submandibular Gland; 5. Sublingual Gland.

ally to the submandibular gland, under the lingual nerve, and was functionally attached to the facial nerve by the chorda tympani nerve. It appeared small and fusiform.

The otic ganglion was situated medially to the mandibular nerve, right under the oval foramen and was functionally attached to the glossopharyngeal nerve. The otic ganglion also had a flattened, small, and oval form (Figure 1).

The comparative study of the anatomical material provided us with some disparities, such as the following: for the submandibular ganglion, we noticed a variation in number and volume of fiber bundles attached to it, as well as its association point to the lingual nerve. In addition, it presented an alteration

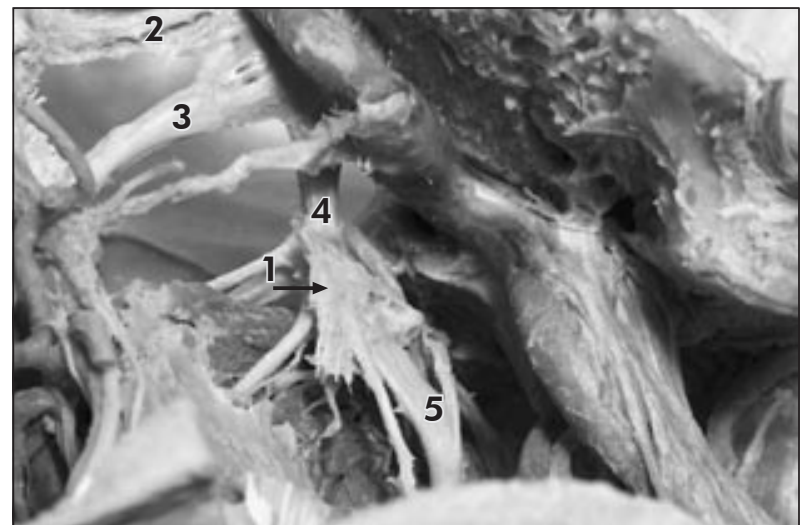

Figure 4 - Medial view of a human head (sagittal section). 1. Otic Ganglion; 2. Ophtalmic Nerve; 3. Maxillary Nerve; 4. and 5. Mandibular Nerve.

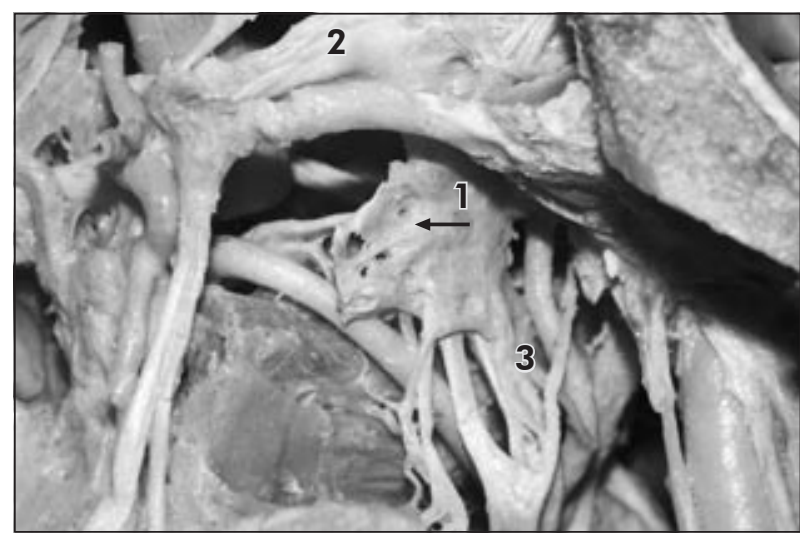

Figure 5 - Medial view of a human head (sagittal section). 1. Otic Ganglion; 2. Maxillary Nerve; 3. Mandibular Nerve.

regarding the proximity to the lingual nerve, ranging from $2 \mathrm{~mm}$ to $6 \mathrm{~mm}$ (Figures 2 and 3).

The otic and pterygopalatine ganglia also showed a disparity regarding number and volume of fiber bundles connected to them. As to the proximity of nerves, the otic ganglion also showed a variation concerning distance to the anterior section of the mandibular nerve, which ranged from 0 to $4 \mathrm{~mm}$ (Figures 4 and 5).

The pterygopalatine and ciliary ganglia did not show any variations in proximity to the maxillary and optic nerve, respectively.

\section{Discussion}

Our results are in agreement with those of other 
studies in the literature, regarding the fact that, in most of the studied human heads, it was observed that the ciliary ganglion is located close to the orbital cavity's apex, between the optic nerve and the lateral rectus muscle..$^{1-5}$

Moreover, in terms of location, our study agrees with the results found by Tsybul'kin ${ }^{6}$ (2003), who observed that the ganglion occupies a posteroinferior, intermediate or anterosuperior position in respect to the common tendinous ring (Zinn's ligament) and optic nerve. This author also found that a posteroinferior position of the ganglion was typical to brachycephals, while the anterosuperior position was found in dolichocephals.

From a morphological point of view, the ciliary ganglion is small and flat, about the size of a pinhead. ${ }^{1}$ This ganglion may also be oval shaped, ${ }^{2}$ quadrilateral shaped, ${ }^{7}$ of irregular form, egg-shaped, or rectangular. ${ }^{4}$ In addition, measuring $1 \mathrm{~mm}$ by $2 \mathrm{~mm}^{2}$ or $3 \mathrm{~mm}$ by $3 \mathrm{~mm},{ }^{8}$ it can be as big as a corn $\operatorname{seed}^{7}$ or be positioned with its largest diameter parallel to the optic nerve's axis. ${ }^{4}$

The ciliary ganglion found in our anatomic specimens was also very small and with a morphology very similar to that described by Warwick, Williams $^{1}$ (1979) and by Dubrul² (1991).

The pterygopalatine ganglion is important for intra-ocular pressure balance and cerebral vasodilatation associated to vascular originated headaches. ${ }^{9}$ It is located deeply in the pterygopalatine fossa, ${ }^{1-3}$ close to the sphenopalatine foramen and in front of the pterygoid canal. ${ }^{1}$

Concerning morphology, there are several descriptions of the pterygopalatine ganglion. According to some researchers, the pterygopalatine ganglion is slightly flat, ${ }^{1,2}$ with a triangular and flat form $^{2}$ and is the biggest peripheral ganglion of the cranial parasympathetic system. However, for others this ganglion is polymorphic, and can be rhomboidal, pear-shaped, semi-lunar, triangular, or fusiform, with volume similar to that of a lentil $(5 \mathrm{~mm}$ to $7 \mathrm{~mm}$ length). ${ }^{7}$ In our study, the pterygopalatine ganglion had a flat form and presented the largest size ( 3 to $5 \mathrm{~mm}$ ); hence, our results concur with the description made by Warwick, Williams ${ }^{1}$ (1979).

According to the literature, the submandibular ganglion is located in the upper part of the hyoglossus muscle. ${ }^{1}$ It is an autonomous nervous structure with reduced dimensions and an aspect that could vary: triangular, egg-shaped, or plexiform. Its size can be compared to that of a lentil or a corn seed; therefore, its dissection is extremely difficult. ${ }^{7}$ Our anatomic pieces showed that the submandibular ganglion is a small, fusiform structure ( 2 to $3 \mathrm{~mm}$ ), which is in accordance with the description made by Warwick, Williams ${ }^{1}$ (1979). While investigating the lingual nerve's relationship to the submandibular ganglion in 32 adult bodies, it was observed that in $46.9 \%$ of the cases, the lingual nerve and the submandibular ganglion were fused, and in $53.1 \%$ they were free..$^{10}$ Our comparative analysis allowed us to observe a variation in the lingual nerve's association point to the submandibular ganglion, yet the fusion of these two anatomic structures was not observed.

The otic ganglion is located directly under the oval foramen..$^{1-3,5}$ Regarding location, our results are in accordance with what is stated in the literature.

Morphologically, the otic ganglion is small, oval, and slightly flat ${ }^{1}$ or has the aspect of a lentil, and its form can have slender variations. ${ }^{7}$ However, our observations concur with the previous description made by Warwick, Williams ${ }^{1}$ (1979), i.e., the otic ganglion seen in our anatomic specimens does not reach the size of a lentil.

Analysis of the otic ganglion in humans describes it as an oval structure, measuring $3.5-4.5 \mathrm{~mm}$ in length, $3 \mathrm{~mm}$ in width, and $1.5 \mathrm{~mm}$ in depth. It was observed that the otic ganglion was present in 18 infratemporal fossae (10 cadavers), having a structure similar to that of the classical description. It was also observed that there are connections between the ganglia and both the lesser petrosal and auriculotemporal nerves. In 13 ganglia, a connecting branch to the medial pterygoid muscle was evident and, in nine other ganglia, a small ramus to the sympathetic plexus of the middle meningeal artery was noted. In most infratemporal fossae, the ganglionic form was seen bilaterally (eight cadavers), although in two instances this form was seen unilaterally, and only a small thickening was found on the contralateral side. This thickening on the medial aspect of the mandibular nerve was seen in two additional infratemporal fos- 
sae in two other cadavers. In the other eight fossae, no specific anatomic structure could be discerned. ${ }^{11}$ Our observations revealed ganglionic forms bilaterally in all the analyzed anatomic specimens.

Nothing was found in the literature in relation to the variation of number and volume of fibers connected to the submandibular, otic, and pterygopalatine ganglia and the proximity of the otic ganglion to the mandibular nerve.

\section{Conclusions}

With this study, we concluded that there was no

\section{References}

1. Warwick R, Williams PL. Gray anatomia. $35^{\mathrm{a}}$ ed. Rio de Janeiro: Guanabara Koogan; 1979.

2. Dubrul EL. Anatomia oral. $8^{a}$ ed. São Paulo: Artes Médicas; 1991.

3. Machado ABM. Neuroanatomia funcional. $2^{\text {a }}$ ed. São Paulo: Atheneu; 1993.

4. Sinnreich Z, Nathan $H$. The ciliary ganglion in man (anatomical observations). Anat Anz. 1981;150(3):287-97.

5. Tortora GJ, Grabowski SR. Princípios de anatomia e fisiologia. $9^{a}$ ed. Rio de Janeiro: Guanabara Koogan; 2002.

6. Tsybul'kin AG. Individual variability of external structure and topography of human ciliary ganglion. Morfologiia. 2003;124(6):34-7. significant variation regarding the location of the studied ganglia. Morphologically, our observations concur with previous classical descriptions of the parasympathetic ganglia, but we observed variations regarding proximity of the otic ganglion to the mandibular nerve. We also observed that there were variations regarding the number and volume of fiber bundles connected to the submandibular, otic, and pterygopalatine ganglia.

\section{Acknowledgments}

We would like to thank Luisa Caliri Juzzo for translating this paper into the English Language.

7. Figún ME, Garino RR. Anatomia funcional odontológica e aplicada. $3^{\text {rd }}$ ed. Rio de Janeiro: Guanabara Koogan; 1994.

8. Izci Y, Gonul E. The microsurgical anatomy of the ciliary ganglion and its clinical importance in orbital traumas: an anatomic study. Minim Invasive Neurosurg. 2006;49:156-60.

9. Oliveira SH, Freire CS, Costa WS, Mandarim-de-Lacerda CA. Anatomic and quantitative study of the human pterygopalatine ganglion: morphometry and stereology. Arq Neuropsiquiatr. 1993;51(2):223-6.

10. Liao J, Lai H, Lu D. Applied anatomical study of the lingual nerve. Zhonghua Kou Qiang Yi Xue Za Zhi. 1996;31:101-3.

11. Roitman R, Talmi YP, Finkelstein Y, Sadov R, Zohar Y. Anatomic study of the otic ganglion in humans. Head Neck. 1990;12(6):503-6. 